\title{
Análise das edições em língua espanhola do romance Manual prático do ódio, de Ferréz ${ }^{1}$
}

\author{
Matheus Oliveira Paiva Curi* e Carolina Geaquinto Paganine**
}

\section{INTRODUÇÃO}

Este artigo ${ }^{2}$ examina as traduções para o espanhol do livro Manual Prático do Ódio (2003) de Ferréz, autor paulista pertencente ao movimento de literatura marginal periférica. Os objetivos deste texto são (i) compreender em que medida os aspectos paratextuais permitiriam entrever aspectos textuais das traduções, (ii) descrever os procedimentos utilizados pelos tradutores para lidar com a variedade linguística e (iii) averiguar em que medida essas técnicas refletiriam o projeto político-literário do autor estudado, projeto esse que busca valorizar a periferia por meio dos temas tratados e da linguagem empregada (FERRÉZ, 2006, n. p.).

Como texto-fonte, toma-se a primeira publicação do Manual prático do ódio (Objetiva, 2003). Como textos-alvo, foram analisadas três obras

\footnotetext{
${ }^{1}$ Apontamentos iniciais desta pesquisa, referindo-se especificamente à análise das traduções do capítulo 1 do livro Manual prático do ódio, foram apresentados na IX Jornada do Programa de Pós-Graduação em Língua Espanhola e Literatura Espanhola e Hispano-Americana (USP). O texto derivado dessa apresentação foi submetido à revista Entrecaminos, filiada a essa mesma universidade. Além disso, submeteu-se resumo ao $19^{\circ}$ Congresso Brasileiro de Professores de Espanhol (UFRN) a ser realizado em outubro de 2021. Para esse evento, o enfoque se centrou nas análises nas traduções dos capítulos 7 e 12 do livro Manual prático do ódio.

${ }^{*}$ Universidade Federal Fluminense/PIBIC CNPq

${ }^{* *}$ Universidade Federal Fluminense

${ }^{2}$ Os autores gostariam de dedicar este texto a Jamil Curi, pai de Matheus Curi, que faleceu durante a elaboração deste artigo. "Embora seja um momento muito difícil, um dos ensinamentos que ele me deixou foi o do esforço. Essa lição foi a que me motivou - e a que me motiva - a continuar. Muito obrigado por tudo, Matheus Curi".
} 
provenientes da Argentina, da Espanha e do México. A tradução espanhola, lançada em 2006 pela editora El Aleph, foi feita por Mario-Jorge Merlino Tornini (doravante Mario Merlino). Em 2011, a editora Corregidor publica o Manual prático do ódio na Argentina, com prólogo e tradução de Lucía Tennina. Finalmente, a última tradução consultada foi feita por Alejandro Reyes e saiu no México, em 2012, pela editora sur+.

A hipótese que circunscreve este artigo é a de que a tradução de variação linguística teria três pontos importantes: (i) a traduzibilidade; (ii) a padronização e (iii) a artificialidade (COLLINS; PONZ, 2018, p. 402-403). Para averiguar como esses pontos se articulam nas obras analisadas, usaram-se os conceitos de procedimentos, estratégias e resultados de Alexandra Assis Rosa (2012). Os procedimentos seriam as técnicas aplicadas na letra do texto traduzido. As estratégias seriam os objetivos atingidos com esses procedimentos. Já os resultados seriam os efeitos causados por esses procedimentos e estratégias nas traduções. Os procedimentos seriam a manutenção, adição, omissão e mudança. As estratégias seriam a padronização, centralização ou descentralização; os resultados seriam a monoglossia ou a heteroglossia.

Em relação à representação da variedade linguística na prosa literária, apoiamo-nos em Milton Azevedo (2003). O autor, em Vozes em Preto e Branco: a representação literária da fala não padrão, divide o fenômeno em quatro "modalidades": regional, situacional, social e temporal (2003, p. 26). Já para organizar essas diferentes manifestações de variação, separamo-las em três marcas de oralidade: fonéticas, lexicais e morfossintáticas, de acordo com a classificação proposta por Paulo Henriques Britto em $A$ tradução literária (2012, p. 92).

Convém ressaltar também que, devido à extensão do romance, realizou-se uma seleção de trechos significativos quanto ao tema e à linguagem que representem "zonas significantes" do romance (BERMAN, 2009, p. 54-57). Assim, escolhemos os capítulos 1, 7 e 12 da obra - composta por 12 no total, levando em consideração a importância que esses capítulos tinham para o enredo. No primeiro, somos apresentados aos protagonistas do romance. No sétimo, dá-se uma pista do que pode ocorrer no final da história. Já no último capítulo, conhecemos o desfecho do assalto ao banco 
planejado pelos protagonistas - mote do livro - e as consequências desse crime para as personagens. Não se ignora, no entanto, que esse método de análise pode excluir compensações feitas pelos tradutores em outros capítulos do livro. Nesse sentido, as conclusões as quais se chega no final deste artigo seriam indicações de tendências tradutórias, não sendo, portanto, definitivas.

\section{FERRÉZ E O MANUAL PRÁTICO DO ÓDIO}

Reginaldo Ferreira da Silva, conhecido como Ferréz, nasceu em 1975 na cidade de São Paulo. Seu nome artístico é a mistura do nome verdadeiro de Lampião (Virgulino Ferreira da Silva) com o de Zumbi dos Palmares: Ferre $+\mathrm{z}$ (Ferreira + Zumbi), unindo, então, dois símbolos de grupos oprimidos ao longo da história brasileira (nordestinos e negros). Antes de se tornar cronista, poeta e romancista profissional, trabalhou como vendedor ambulante, balconista e chapeiro. Em 1997, publica sua primeira obra: Fortaleza da Desilusão - livro de poesia concreta. Com o lançamento de Capão Pecado, em 2000, o autor ganha notoriedade pelo modo como aborda o cotidiano do Capão Redondo, bairro periférico da cidade de São Paulo onde morou durante muitos anos (Enciclopédia Itaú Cultural de Arte e Cultura Brasileiras, 2021, n.p.).

Em 2003, publica-se Manual prático do ódio, o segundo romance do autor. Nele, conta-se a história de um assalto a banco, protagonizado por Aninha, Celso Capeta, Lúcio Fé, Mágico, Neguinho da Mancha na Mão e Régis. Cada uma dessas personagens tem seus dilemas existenciais e seus motivos para ter ingressado ao mundo do crime. Embora a história tenha como tema de fundo o assalto, o objetivo do autor é descrever como o ódio é plantado e germinado nos moradores tanto da quebrada, termo utilizado para se referir às favelas da cidade de São Paulo, quanto dos lugares mais abastados. Um verdadeiro "manual" que explicaria a sociedade desigual e violenta na qual vivemos. Haveria na história, então, duas perspectivas principais: a da violência e a da denúncia social.

Do ponto de vista formal, a linguagem do livro parece misturar-se ao "ritmo do bairro" - ou ao modo como a dinâmica dos acontecimentos se dá no bairro. Emilio Sadier, em Narrar el margen: visibilidades, ritmos y juegos, 
divide esse ritmo entre velocidade/surpresa (2013, p. 27-29) e continuidade/reprodução social (idem, p. 29-31). O primeiro conjunto de conceitos se relacionaria com a maneira rápida, dinâmica, violenta e inesperada como as coisas acontecem na quebrada descrita no Manual prático do ódio. De acordo com Sadier, essa velocidade se amalgamaria com a própria caracterização das personagens. $O$ segundo conjunto se relacionaria, contudo, com os mecanismos que manteriam a vida social em ordem. A relação ambígua e complementar entre esses dois conjuntos de conceitos seria a responsável por manter o ritmo do bairro.

O ritmo do bairro, então, seria transposto ao ritmo do texto. A fragmentação, o uso exagerado de vírgulas, o uso de orações de uma só palavra, de flashbacks e de elipses seriam, de acordo com Sadier (2013, p. 35), algumas características de como a velocidade do bairro seria transposta à forma do texto. Ao mesmo tempo, capítulos como o quinto, no qual se narra a história de amor "telenovelesca" de Celso Capeta, quebrariam a velocidade e a dinâmica do próprio texto, deixando a trama - e o leitor, consequentemente - em modo de espera (SADIER, 2013, p. 35-36). O jogo entre velocidade e continuidade, portanto, seria um jogo entre aceleração e lentidão; urgência e espera.

Em relação aos aspectos editorais do livro, Manual prático do ódio teve, até o momento da publicação deste artigo, duas edições: a primeira foi lançada pela editora Objetiva em 2003 e a segunda pela editora Planeta em 2014. A principal diferença, em termos de forma, é a revisão textual feita de uma edição para a outra. Notam-se mudanças de grafia, de pontuação e supressões de alguns trechos.

Já em relação aos aspectos peritextuais, definidos por Gerard Genette (2009, p. 21) como uma categoria de paratexto que privilegia os elementos materiais e técnicos do livro editado, exteriores ao texto literário em si, encontram-se também diferenças entre as edições. A primeira delas seria a capa das duas publicações. Na primeira edição, vê-se uma criança negra com asas em uma quebrada. Na segunda, alguém está sacando um revólver da cintura. 
Figura 1 e 2: $1^{\underline{a}}$ e $2^{2}$ edições, respectivamente, do Manual prático do ódio publicadas no Brasil (2003 e 2014)

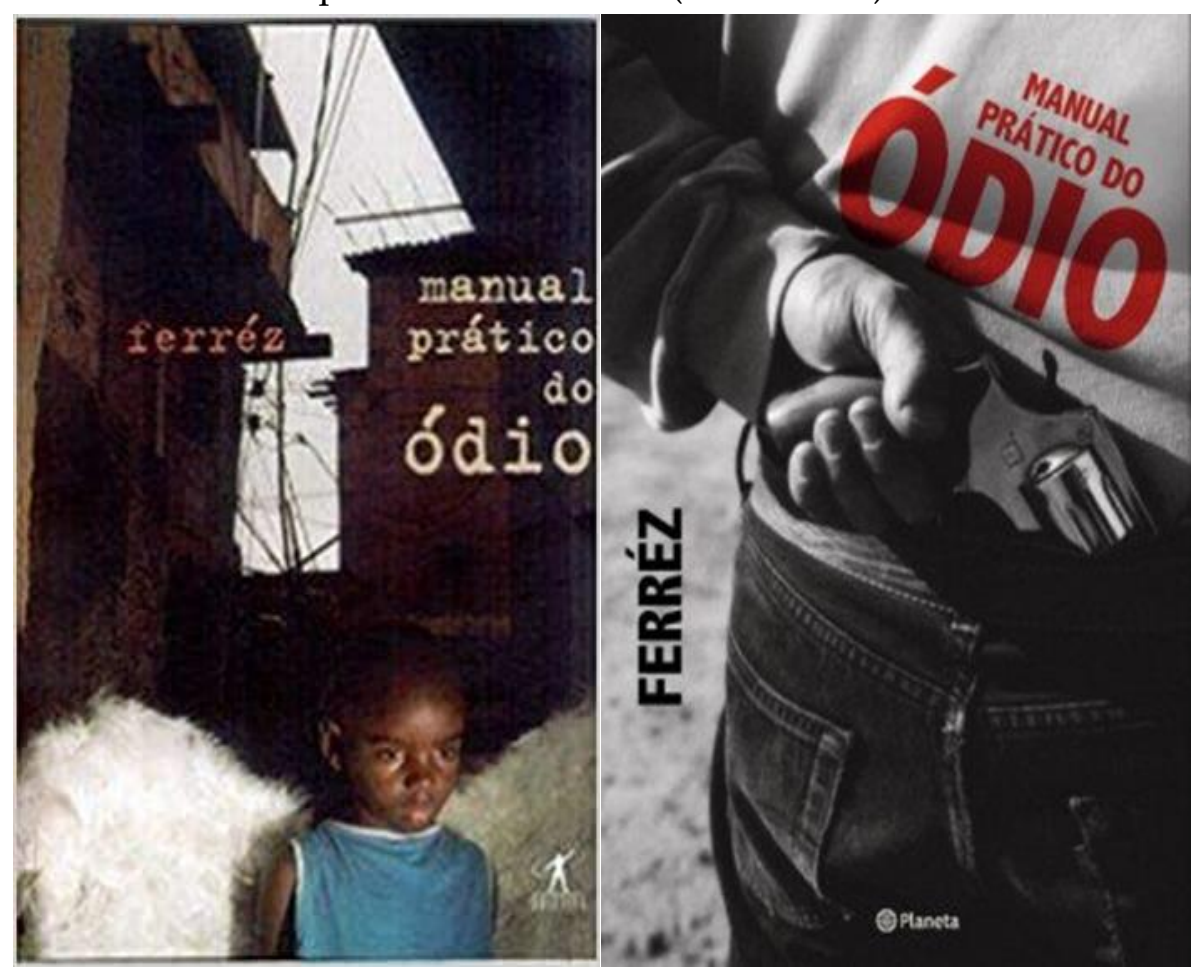

Fontes: Páginas de venda dos livros na Amazon Brasil ${ }^{3}$ e na Planeta de livros 4 .

Essas duas imagens, postas lado a lado, contrastam completamente. A capa da primeira edição, assim como afirma Ferréz (2020), inspira-se no anjo da 1DASUL, um dos símbolos da marca de roupa que o autor criou em 1999. A marca teria dois símbolos: o primeiro seria formado pelo número 1 envolto em asas de fênix; o segundo seria um jovem anjo negro (similar à capa vista acima). Segundo o autor (FERRÉZ, 2005, n.p.), o brasão da 1DASUL (o número 1 envolto em asas), simbolizaria a união do povo periférico que, durante muito tempo, foi dividido pelos colonizadores. Se damos ao segundo símbolo, o anjo, o mesmo significado do primeiro, poderíamos dizer, então, que esse simbolizaria a união do povo periférico ante todas as situações que têm de passar na quebrada, sejam elas boas ou más.

\footnotetext{
${ }^{3}$ Disponível em: https://www.amazon.com.br/Manual-Pratico-Do-Odio-Ferrez/dp/8573025646. Acesso em: 02 jun. 2021.

${ }^{4}$ Disponível em:

https://www.planetadelivros.com.br/livro-manual-pratico-do-odio/167403. Acesso em: 02 jun. 2021.
} 
A segunda capa, no entanto, apresentaria o lado violento do livro, exposto no próprio título. Como a imagem usada sugere um movimento - alguém sacando uma arma -, a ênfase recai sobre o aspecto cinematográfico da narrativa de Ferréz. Ou seja, uma obra com uma prosa rápida, repleta de ações, com trocas constantes de cenas. Poderíamos dizer, então, que enquanto a primeira capa se aproximaria dos aspectos documental e de denúncia social presentes no livro, a segunda se aproximaria dos aspectos cinematográfico e narrativo da trama.

\section{OS PARATEXTOS: OS TRADUTORES E AS EDIÇÕES}

A seguir, analisaremos características paratextuais das traduções do Manual prático do ódio para a língua espanhola e buscaremos entender quais pistas essas características dão acerca das traduções feitas e dos fatores de controle de cada sistema literário no qual essas traduções estão inseridas.

A primeira tradução para a língua espanhola foi publicada em 2006 pela editora El Aleph, em Barcelona, Espanha. A edição apresenta 16 notas de rodapé e não contém glossário. Mario Merlino (1948-2009), o tradutor dessa edição, foi um profissional reconhecido nesse país, tendo traduzido principalmente obras de língua portuguesa para o espanhol.

A capa, como se pode ver na figura 3, apresenta um fundo negro e um revólver apontado para o desconhecido. Além disso, há uma citação que diz "O novo trovador dos subúrbios de São Paulo" 5 (2006, n.p.). Os textos da primeira orelha e da contracapa são traduções dos peritextos existentes na primeira edição do livro em português. Essa descrição nos permitiria supor que o enfoque dado ao romance seria aquele relacionado à violência das periferias brasileiras. O "novo trovador dos subúrbios de São Paulo", aquele que conheceria essa violência in loco, viria contar ao leitor espanhol o que se passa nas quebradas paulistas.

\footnotetext{
5 "El nuevo trovador de los suburbios de São Paulo". A tradução desta citação, assim como as demais nas quais não houver indicação do tradutor, são de nossa autoria.
} 
Figura 3: Tradução do Manual prático do ódio publicada na Espanha (2006).

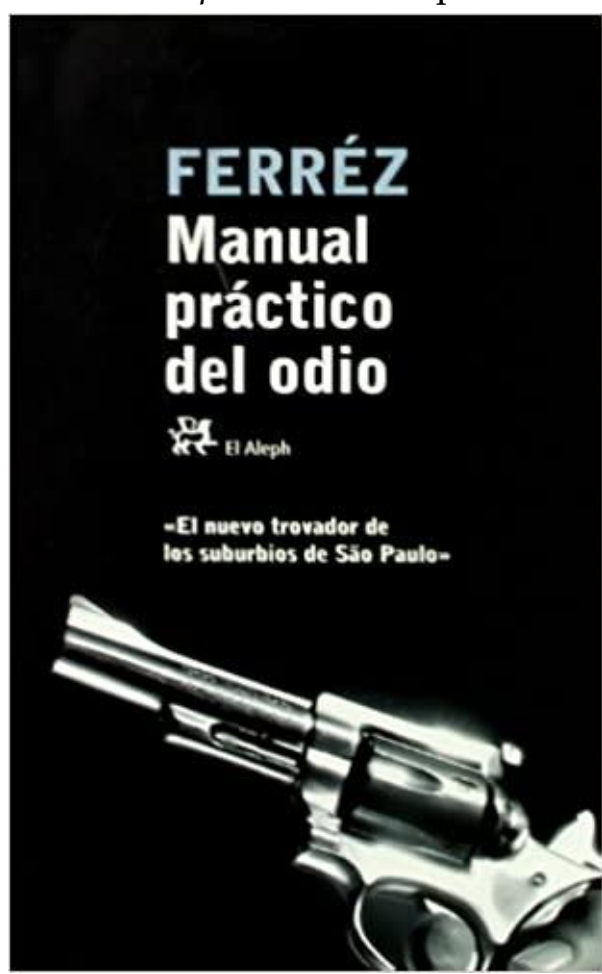

Fonte: Página de venda do livro na Amazon Brasil ${ }^{6}$

A segunda tradução foi publicada em $2011^{7}$, pela editora Corregidor, e foi traduzida por Lucía Tennina, professora da Universidad de Buenos Aires. Essa tradução está inserida na coleção Vereda Brasil, que reúne autores canônicos da literatura brasileira como Clarice Lispector e Machado de Assis. Segundo Faria (2016, p. 34), essa coleção - assim como outras da mesma editora - seriam caracterizadas (i) pela participação de professores universitários e críticos literários na organização dessas edições e (ii) pela presença de paratextos editoriais.

Ainda segundo Faria, a origem da coleção Vereda Brasil “esteve subordinada à cátedra de Literatura Brasileira e Portuguesa da Universidad

\footnotetext{
${ }^{6}$ Disponível em:

https://www.amazon.com.br/Manual-pr\%C3\%A1ctico-del-odio-Ferrez/dp/8476697376. Acesso em: 03 de junho de 2021.

${ }^{7}$ Convém ressaltar que essa edição foi revisada e republicada em 2019. Essa segunda publicação, contudo, não foi analisada.
} 
de Buenos Aires" (FARIA, 2016, p. 34). Isso explicaria a participação de Tennina, professora da instituição, na tradução do livro. A tradutora é estudiosa da literatura marginal, tendo livros e artigos publicados sobre o tema.

A edição contém prefácio da tradutora, glossário com 58 termos ${ }^{8}, 65$ notas de rodapé ${ }^{9}$ e quatro textos de diferentes espectros da crítica literária. Importante ressaltar que o primeiro parágrafo da contracapa é uma tradução do que vem escrito na contracapa do livro-fonte. A capa dessa edição utiliza uma tipografia típica do grafite para fazer referência ao universo da periferia.

Figura 4: Tradução do Manual prático do ódio na Argentina (2011).

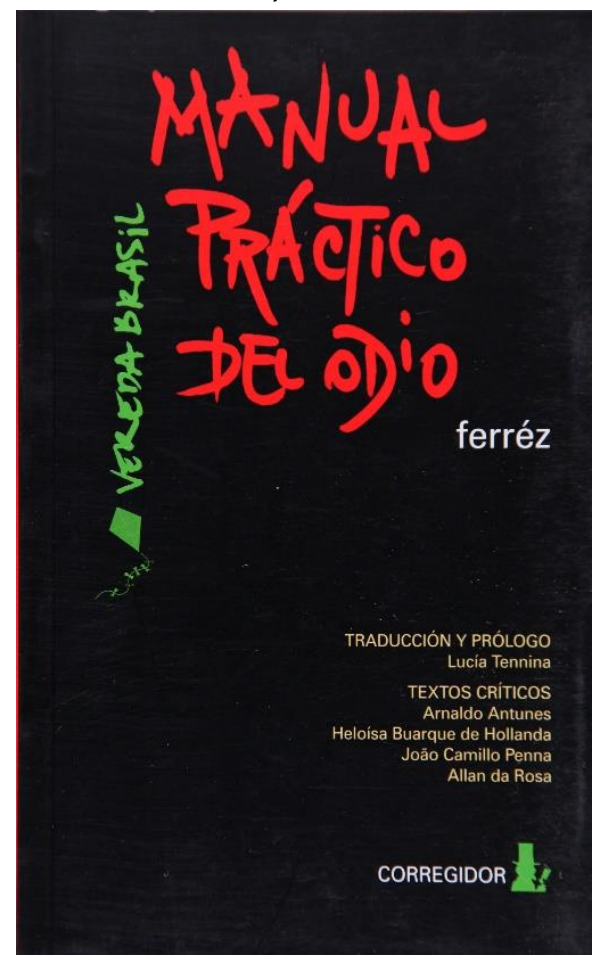

Fonte: Página de venda do livro na Amazon ${ }^{10}$.

\footnotetext{
8 Em relação à edição argentina, excluíram-se da contagem os termos referentes a nomes e a siglas, pois estão em seções distintas do glossário. A título de informação, constam nove entradas de nomes e 12 entradas de siglas.

${ }^{9}$ Ainda em relação à edição argentina, excluíram-se da contagem as sete notas de rodapé do prólogo da tradutora e as 20 encontradas ao longo dos textos críticos no final do livro.

${ }^{10}$ Disponível em: https://www.amazon.com/Manual-practico-del-odio-Spanish/dp/9500519666. Acesso em: 02 de junho de 2021.
} 
A última tradução é a mexicana, lançada em 2012 pela editora independente sur+ que, em um manifesto, explicita alguns dos seus objetivos editoriais. Um deles seria revalorizar "o sul social em um mundo dominado pelo norte"11; outro seria buscar "somar-se às redes do sul social promovendo o intercâmbio de experiências e vinculando movimentos literários contemporâneos"12 (2018?, n.p.). Nota-se, portanto, que a editora pretenderia difundir poéticas que se oporiam ao status quo; ou ao "norte", entendido como os países ricos situados nessa parte do hemisfério.

Outro fator importante a salientar é que essa edição foi financiada por programas brasileiros e mexicanos de fomento. A tradução recebeu apoio do Ministério da Cultura do Brasil e da Fundação Biblioteca Nacional, por meio do Programa de Apoio à Tradução e à Publicação de Autores Brasileiros no Exterior. Já o programa de fomento mexicano que auxiliou na publicação do livro foi o Fondo Nacional para la Cultura y las Artes, por meio do Programa de Coinversiones para proyectos culturales.

O tradutor dessa edição é Alejandro Reyes, que é também é escritor e estudioso da literatura marginal. Em 2013, lançou pela editora Aeroplano o livro Vozes dos porões: a literatura periférica/marginal do Brasil, derivado de seus estudos sobre esse movimento literário.

A tradução, que inicialmente teria sido negociada como livro de bolso (FERRÉZ, 2020), contém ainda 23 notas de rodapé e um glossário com 20 termos. A capa destoa das demais, não fazendo referência explícita a nenhum aspecto do universo do autor ou dos temas tratados na obra. Como se pode ver na figura abaixo, o "furo" no centro da capa parece ter sido produzido por um tiro, mas essa referência, em um primeiro momento, não seria evidente.

\footnotetext{
11 “[...] el sur social en un mundo dominado por el norte $[\ldots]$ ";

12 "[...] sumarse a las redes del sur social promoviendo el intercambio de experiencias y vinculando movimientos literarios contemporáneos.";
} 
Figura 5: Tradução do Manual prático do ódio publicada no México (2012).

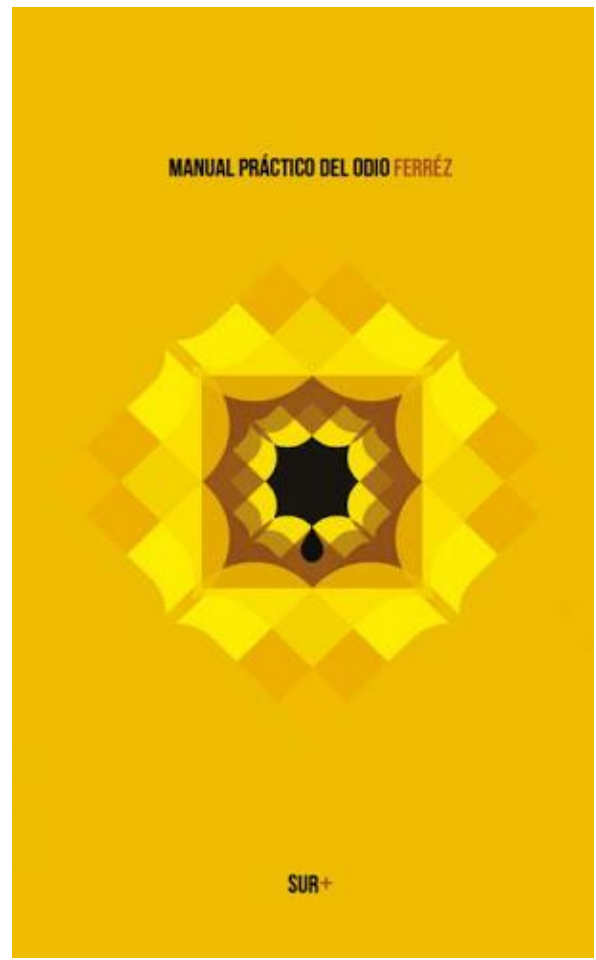

Fonte: Página de venda do livro na sur ${ }^{13}$

Até aqui, pressupõe-se, então, que os aspectos paratextuais e editorais das traduções apontariam ao seguinte: (i) a tradução europeia, pelo baixo número de notas de rodapé e pela ausência de glossário, poderia ser mais domesticadora; (ii) a tradução mexicana poderia estar em um nível intermediário, pois ainda que tenha glossário e mais notas de rodapé, foi idealizada para ser um livro de bolso e (iii) a tradução argentina, pela sua vinculação editorial e pela quantidade de paratextos editorais, seria mais acadêmica e, em certa medida, mais estrangeirizadora.

${ }^{13}$ Disponível em: http://www.surplusediciones.com/libro/manual-practico-del-odio. Acesso em: 02 de junho de 2021. 


\section{OS TEXTOS TRADUZIDOS}

O primeiro trecho selecionado para análise pertence ao capítulo um e trata dos preparativos para uma saída da personagem Neguinho da Mancha da Mão. Nota-se, no texto-fonte, um narrador que, assim como as personagens, utiliza gírias e um ritmo rápido de narrativa.

Quadro 1: Neguinho da Mancha na Mão indo para o baile

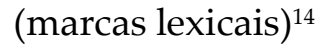

\begin{tabular}{|c|c|}
\hline - & leph Editores, 2006. p. \\
\hline $\begin{array}{l}\text { No ônibus retornando para casa, } \\
\text { bassou o tempo inteiro olhando } \\
\text { pela janela e imaginando seu rolè à } \\
\text { toite, nada de treta, nada de andar } \\
\text { om homem, hoje era o dia em que } \\
\text { Neguinho da Mancha na Mão iria } \\
\text { para baile conhecer alguém, ou } \\
\text { nelhor, ia pro fecha-nunca, o risca- } \\
\text { aca, o mela-cueca ou simplesmente } \\
\text { lava-rápido que vivia cheio de } \\
\text { nulheres. }\end{array}$ & $\begin{array}{l}\text { el día en que Negu } \\
\text { na Mão iría al bai } \\
\text { alguien o, mejor, iría } \\
\text { echarse un polve } \\
\text { llanamente, al put } \\
\text { lleno de muieres. }\end{array}$ \\
\hline $\begin{array}{l}\text { RRÉZ. Manual práctico del odio. } \\
\text { Lucía Tennina. Buenos Aires: } \\
\text { rregidor, 2011. Vereda Brasil; } 23 . \\
\text { 32-33. }\end{array}$ & 26. \\
\hline $\begin{array}{l}\text { En el ómnibus volviendo a } \\
\text { casa, se pasó todo el tiemp } \\
\text { nirando por la ventanilla }\end{array}$ & En el autobús de regreso se pasc \\
\hline
\end{tabular}

\footnotetext{
14 Todas as partes em negritos são grifos nossos, buscando facilitar a localização pelo leitor das marcas que serão analisadas nos parágrafos seguintes;
} 
nada de peleas, nada de andar con hombres, era el día en el que Neguinho da Mancha na Mão iba a ir al baile a conocer a alguien, o mejor, iba a un "nunca-cierra", a un "afila-cuchillo", a un "mojacalzón" o simplemente a un lavaautos que siempre estaban llenos de mujeres. de salir con hombres, hoy Neguiño da Mancha na Mão iría al baile a conocer a alguien o, mejor, al after, a algún bar de mala muerte, a algún salón de faje o simplemente al autolavado, que vivía lleno de mujeres.

Quanto ao estilo de escrita de Ferréz, percebe-se que todos os tradutores buscaram seguir a pontuação do original. Já quanto às marcas lexicais, há diferenças. 'Rolê' e 'treta' são traduzidos por palavras com significados mais ou menos equivalentes, porém menos coloquiais que as originais - 'confusión', 'pelea', 'tontería' e 'salida'. No momento em que o narrador descreve como Neguinho na Mancha na Mão imaginava seu 'rolế', usam-se os termos 'fecha-nunca', 'risca-faca' e 'mela-cueca'. Para traduzi-los, utilizam-se diferentes procedimentos tradutórios. A tradutora argentina faz uma tradução literal dos termos em português, apoiando-se em notas de rodapé para descrever os significados dessas palavras, enquanto os demais tradutores utilizam termos coloquiais. Aparentemente, os vocábulos usados por Ferréz seriam ambíguos, contendo tanto referências sexuais quanto referências a tipos de bares. Os três termos, 'fecha-nunca', 'risca-faca' e 'mela-

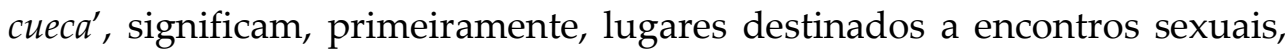
mas 'fecha-nunca' e 'risca-faca', podem ser também, respectivamente, um lugar que funciona a noite toda ou onde há muitas brigas. Na tradução peninsular, privilegia-se o primeiro grupo de significados. Já na tradução mexicana, privilegia-se o segundo. Pode-se dizer, nesse sentido, que na primeira parte do parágrafo todos os tradutores omitem ${ }^{15}$ marcas lexicais do original. Já na segunda, usam o procedimento de manutenção.

\footnotetext{
${ }^{15}$ Os itálicos nas palavras omitir, mudar, manter e adicionar - e derivados - fazem alusão aos procedimentos elencados por Assis Rosa (2012, p. 85).
} 
O fragmento seguinte advém do primeiro parágrafo da seção que apresenta Lúcio Fé. Em relação às marcas lexicais, encontramos no textofonte expressões como 'cara', 'mano', 'quebrada', '121', 'vira e mexe', 'rapaziada' e 'bicho'. Na tradução de Merlino, algumas dessas marcas são mantidas, como 'tío', 'tipo', outras são adicionadas, como 'chavalín' para 'pequeno' - havendo aqui uma compensação - e outras, ainda, são omitidas, como '121', 'vira e mexe', 'rapaziada', 'bicho' e 'quebrada'.

Deve-se ressaltar que uso dos artigos do Código Penal para se referir a crimes é uma característica importante da linguagem nessa narrativa, já que aludiria implicitamente a esses delitos - sendo, então, uma espécie de 'língua criptografada'. A omissão do termo 'quebrada' também é importante, pois essa palavra se relaciona explicitamente com o território que se quer valorizar nesse livro. No caso da tradução de Merlino, nem mesmo se usam vocábulos mais gerais como 'favela' para se referir à quebrada. Generalizase, assim, a quebrada a uma mera ' $z o n a^{\prime}$. O termo 'favela', no entanto, aparece na tradução quando se usa essa palavra no texto-fonte.

Quadro 2: Descrição de Lúcio Fé (marcas lexicais)

\begin{tabular}{|c|c|}
\hline $\begin{array}{l}\text { RREZ. Manual prático do ódio. } \\
\text { de Janeiro: Objetiva, 2003. p. } 26 .\end{array}$ & $\begin{array}{l}\text { FERREZ. Manual práctico del odio. } \\
\text { Tr. Mario Merlino. Barcelona: El } \\
\text { Aleph Editores, 2006. p. 26-27. }\end{array}$ \\
\hline $\begin{array}{l}\text { Lúcio Fé ainda chuta coisas na rua, } \\
\text { até hoje chuta, os caras passavam a } \\
\text { mão na sua cabeça, hoje ele passa na } \\
\text { cabeça dos pequenos, adora criança, } \\
\text { tem uma penca de afilhados, não } \\
\text { havia mano mais considerado na } \\
\text { quebrada, mas fazia uns } 121 \text { pra } \\
\text { viver, ou seja, vira e mexe matava } \\
\text { alguém por dinheiro. Freqüentava a } \\
\text { igreja todos os domingos, tinha } \\
\text { muita fé, seu apelido fora posto } \\
\text { ainda pequeno e no latrocínio só } \\
\text { dava ele, linha de frente em }\end{array}$ & $\begin{array}{l}\text { Lúcio Fé aún patea cosas en la calle, } \\
\text { hasta hoy sigue pateando, los tíos le } \\
\text { acariciaban la cabeza, hoy él } \\
\text { acaricia a los pequeños, le encantan } \\
\text { los ninõs, tiene un montón de } \\
\text { ahijados, no había tipo mejor } \\
\text { considerado en la zona, pero se } \\
\text { quitaba gente de encima para vivir, } \\
\text { o sea alguna que otra vez mataba a } \\
\text { alguien por dinero. Iba a la iglesia } \\
\text { todos los domingos, tenía mucha fe, } \\
\text { lo llaman Fé desde que era un } \\
\text { chavalín y cuando se trataba de }\end{array}$ \\
\hline
\end{tabular}




\begin{tabular}{|c|c|}
\hline $\begin{array}{l}\text { qualquer parada, encabeçava os } \\
\text { assaltos sem olhar para trás, a } \\
\text { rapaziada que corria com ele estava } \\
\text { segura, diziam por aí que o bicho } \\
\text { tinha pacto com o cão, sua fama } \\
\text { aumentou mais na quebrada } \\
\text { quando se envolveu com Régis, } \\
\text { Aninha e Celso Capeta. }\end{array}$ & $\begin{array}{l}\text { robar llevaba la delantera en } \\
\text { cualquier atraco, encabezaba los } \\
\text { asaltos sin mirar atrás, los } \\
\text { muchachos que iban con él estaban } \\
\text { seguros, decían por ahí que tenía un } \\
\text { pacto con el diablo, su fama } \\
\text { aumentó más en la zona cuando se } \\
\text { juntó con Régis, Aniña y Celso } \\
\text { Capeta. }\end{array}$ \\
\hline (2) & 31. \\
\hline $\begin{array}{l}\text { Lucio Fé aún patea cosas por la } \\
\text { calle, hasta hoy patea, los tipos } \\
\text { pasaban la mano por su cabeza, } \\
\text { ahora es él quien la pasa por la } \\
\text { cabeza de los chicos, adora a los } \\
\text { niños, tiene un montón de ahijados, } \\
\text { no había mano más considerado } \\
\text { que él en la quebrada, aunque hacía } \\
\text { algunos } 121 \text { para vivir, o sea, cada } \\
\text { dos por tres mataba a alguien por } \\
\text { dinero. Iba a la iglesia todos los } \\
\text { domingos, tenía mucha fe, suapodo } \\
\text { se lo pusieron de chico y en los } \\
\text { latrocinios era la figura central, } \\
\text { primera fila en cualquier jugada, }\end{array}$ & $\begin{array}{l}\text { Lúcio Fé aún patea cosas en la calle, } \\
\text { hasta hoy sigue pateando, antes los } \\
\text { hombres le acariciaban la cabeza, } \\
\text { hoy él se la acaricia a los chicos, le } \\
\text { encantan los niños, tiene un montón } \\
\text { de ahijados, no hay camarada más } \\
\text { querido en la favela, pero hace } \\
\text { algunos } 121 \text { para vivir, o sea que de } \\
\text { vez en cuando mata gente por } \\
\text { dinero. Va a la iglesia todos los } \\
\text { domingos, tiene mucha fe, desde } \\
\text { chico lo apodaron así, y para los } \\
\text { asaltos no hay otro igual, siempre } \\
\text { en la delantera, encabeza las } \\
\text { acciones sin mirar atrás, la banda } \\
\text { que vaya con él está segura, dicen } \\
\text { por ahí que el bicho tiene un pacto } \\
\text { con el diablo, su fama en la favela } \\
\text { aumentó aún más cuando se } \\
\text { involucró con Régis, Aninha y } \\
\text { Celso Capeta. }\end{array}$ \\
\hline
\end{tabular}


quebrada cuando se metió con Régis, Aninha y Celso Capeta.

Lucía Tennina mantém os termos 'tipo', 'mano', 'quebrada', '121', 'banda' e 'loco' e omite a expressão coloquial 'vira e mexe' para 'cada dos por tres'. Notase que a autora usa estrangeirismos, seguidos de notas de rodapé ou de glossário, para manter certos aspectos do modo de falar periférico, como o uso de artigos do Código Penal e a referência territorial específica à quebrada. Já Alejandro Reyes mantém os termos 'camarada', '121', 'banda' e 'bicho', muda o termo 'quebrada' para 'favela', generalizando, dessa forma, o local onde se passa a história. Além disse, omite as palavras 'hombres' e 'de vez em cuando'.

O terceiro trecho trata do último diálogo do primeiro capítulo da obra. Esse acontece entre o antagonista da história - Modelo - e outro criminoso não nomeado. Em relação às marcas fonéticas, Tennina mantém apenas o estrangeirismo 'homi', que pode ser considerado também uma marca morfossintática, já que traz ao texto espanhol a não-concordância entre sintagma nominal e verbo. Já Merlino mantém apenas a interjeição ' $a h^{\prime}$ para 'ai'. Reyes, por sua vez, mantém a interjeição ' $e h^{\prime}$ para 'hein' e 'tons' (entonces) para 'aí.

Quadro 3: Diálogo entre Modelo e outro bandido (marcas fonéticas, lexicais e morfossintáticas) ${ }^{16}$

\begin{tabular}{|c|c|}
\hline $\begin{array}{l}\text { FERREZ. Manual prático do ódio. } \\
\text { Rio de Janeiro: Objetiva, 2003.p. } 29 .\end{array}$ & $\begin{array}{l}\text { Tr. Mario Merlino. Barcelona: El } \\
\text { Aleph Editores, 2006. p. 29-30. }\end{array}$ \\
\hline $\begin{array}{l}\text { - E o que pegou com o Primo? Ele } \\
\text { num ia junto? } \\
\text { - O Primo assinou } 180 \text { de graça, } \\
\text { mano ligeiro mas vacilou, pegou }\end{array}$ & $\begin{array}{l}\text { - ¿Y qué pasó con Primo? ¿N } \\
\text { estaba con ellos? } \\
\text { - Primo declaró haber robado si }\end{array}$ \\
\hline
\end{tabular}

${ }^{16} \mathrm{~A}$ segunda e a terceira falas deste exemplo também foram comentadas no artigo "Os tradutores são mais confiáveis: a variação linguística nas traduções para o espanhol do capítulo um de Manual prático do ódio" (CURI, 2021, no prelo). 


\begin{tabular}{|c|c|}
\hline $\begin{array}{l}\text { e ele assinou. } \\
\text { - Firmeza, Modelo. Aí, liga nóis se } \\
\text { precisar, hein, vou falar, quando cê } \\
\text { quiser trombar aqueles maluco lá } \\
\text { de cima, liga eu, favor por favor, cê } \\
\text { tá ligado. } \\
\text { - Esquenta não, tru, deixa engordar, } \\
\text { quando tiver fortão, nós derruba, } \\
\text { agora pega o esquema aí e resolve }\end{array}$ & $\begin{array}{l}\text { vaciló, cogió un coche prestado, los } \\
\text { polis lo detuvieron y él declaró. } \\
\text { - Vale, Modelo. Ah, llámanos si } \\
\text { hace falta, ya te digo: cuando } \\
\text { quieras cargarte a esos tíos de ahí } \\
\text { arriba, llámame, un favor trae otro, } \\
\text { ya sabes. } \\
\text { - No te calientes, compañero, crece } \\
\text { un poco más y, cuando estés fuerte, } \\
\text { nos los cargamos, ahora sigue el } \\
\text { plan y resuelve tu problema. } \\
\text { - Vale. }\end{array}$ \\
\hline Tr. & 5. \\
\hline $\begin{array}{l}\text { - ¿Y en qué anda el primo? ¿Él no te } \\
\text { acompañaba? } \\
\text { - El Primo firmó el } 180 \text { por nada, es } \\
\text { un tipo rápido pero estuvo flojo, } \\
\text { tomó un auto prestado, los homi lo } \\
\text { agarraron y él firmó. } \\
\text { - Firmeza, Modelo. Llamanos si } \\
\text { necesitás, ¿sí? te digo, cuando } \\
\text { quieras derribar a esos locos de allá } \\
\text { arriba, llamame, favor por favor, ¿se } \\
\text { entiende? } \\
\text { - No te calientes, bro, que engorden } \\
\text { y cuando estén fuertes, los } \\
\text { derribamos, ahora tomá estas cosas } \\
\text { y resolvé tu problema. }\end{array}$ & $\begin{array}{l}\text { - El Primo firmó confesión por } \\
\text { nada, el mano es rápido pero vaciló, } \\
\text { tomó carro prestado, la tira lo } \\
\text { agarró y él firmó. } \\
\text { - Firmeza, Modelo. Tons, llámanos } \\
\text { si nos necesitas, ¿eh?, te voy a decir, } \\
\text { cuando quieras tumbarte a esos } \\
\text { malandros de arriba, llámame, por } \\
\text { favor, ¿agarras? } \\
\text { - Tranquilo, mano, deja que crezcas } \\
\text { un poco, cuando estés bien fuerte }\end{array}$ \\
\hline
\end{tabular}


Quanto às marcas lexicais, Merlino mantém os termos 'tío' e 'polis'17 e omite '180', 'tá ligado' e 'tru'. Além disso, muda 'firmeza' para 'vale'. Denominamos o último procedimento como mudança porque a expressão 'vale' é um termo coloquial do espanhol mais usado e socialmente aceito do que o termo 'firmeza' em português. Tennina mantém os termos '180', 'tipo', 'firmeza', 'locos' e 'bro'. A tradutora omite 'tá ligado'. Reyes, por sua vez, mantém os termos 'mano', 'tira', 'firmeza', 'malandros', 'agarras' e 'fierro'. Omite, no entanto, o termo '180' ao usar 'firmó confesión'. Tanto no caso de Reyes como no de Merlino, as omissões demonstram problemas de interpretação, pois o artigo 180 se refere à receptação de objetos roubados, não a confissão nem a roubo.

Já o fragmento a seguir, retirado do capítulo 7, trata de uma visita das personagens Celso Capeta e Régis ao pai de santo Joel. Eles queriam descobrir se o assalto planejado conseguiria ser realizado ou não. Essa cena daria uma pista do que acontecerá nos próximos capítulos da história.

Quadro 4: Diálogo entre Celso Capeta, Pai Joel e Régis (marcas fonéticas e lexicais)

\begin{tabular}{|l|l|}
\hline FERRÉZ. Manual prático do ódio. & FERRÉZ. Manual práctico del odio. \\
Rio de Janeiro: Objetiva, 2003.p. 121. & $\begin{array}{l}\text { Tr. Mario Merlino. Barcelona: El } \\
\text { Aleph Editores, 2006. p. 108. }\end{array}$ \\
\hline - Oi, pai. & - Hola, padre. \\
- Eh! Oi, seu Joel. & - Hola, señor Joel. \\
- Você meu fiu, num me chama de & - Tú eres mi hijo, no me llames \\
senhor não, só de pai. & señor, llámame padre. \\
- Tá bom! & - Vale. \\
- Vocês são do quime né? & - Vosotros estáis en el quimen, no? \\
- Quime? & - ¿Quimen? \\
& \\
\hline
\end{tabular}

${ }^{17}$ No artigo 'Os tradutores são mais confiáveis: a variação linguística nas traduções para o espanhol do capítulo um de Manual prático do ódio' (CURI, 2021, no prelo), mostra-se a evidência de que os acortamientos (abreviações) poderiam ser marcas lexicais mais bem aceitas nas traduções. No entanto, como não foram encontrados outros textos que corroborassem com essa tese, definimos os acortamientos como procedimentos de manutenção. 


\begin{tabular}{|c|c|}
\hline $\begin{array}{l}\text { - Porra, Régis, ele fala assim } \\
\text { mesmo. } \\
\text { - Ah! Tá. } \\
\text { - Vocês são do quime eu sei. } \\
\text { - É. Somos sim, eu e meu parceiro } \\
\text { aqui. } \\
\text { - Bom, ceis qué algo, eu sei o quê, } \\
\text { mas o destino é estanho, meu fio, } \\
\text { nunca se sabe quem é quem. Vocês } \\
\text { qué sabê se o quime vai dá certo, } \\
\text { mas tem um perdido, tá vagando e } \\
\text { tá atrás de você. }\end{array}$ & $\begin{array}{l}\text { - Joder, Régis, él habla así. } \\
\text { - ¡Ah, bien! } \\
\text { - Vosotros estáis en el quimen, lo } \\
\text { sé. } \\
\text { - Sí. Los dos, mi compañero y yo. } \\
\text { - Bien, vosotros queréis algo, yo sé } \\
\text { qué, pero el destino es estaño, hijo } \\
\text { mío, nunca se sabe quién es quién. } \\
\text { Vosotros queréis saber si el quimen } \\
\text { va a salir bien, pero hay un alma } \\
\text { perdida, está vagando y está detrás } \\
\text { de ti. }\end{array}$ \\
\hline $\begin{array}{l}\text { FERRÉZ. Manual práctico del odio. } \\
\text { Tr. Lucía Tennina. Buenos Aires: } \\
\text { Corregidor, 2011. Vereda Brasil; } 23 . \\
\text { p. } 133 \text {. }\end{array}$ & $\begin{array}{l}\text { FERRÉZ. Manual práctico del odio. } \\
\text { Tr. Alejandro Reyes. Oaxaca: sur+ } \\
\text { ediciones, 2012. p. } 138 \text {. }\end{array}$ \\
\hline $\begin{array}{l}\text { - Hola. } \\
\text { - Hola, señor Joel. } \\
\text { - Mijo, no me trate de señor, solo de } \\
\text { pai. } \\
\text { - Bueno } \\
\text { - Ustedes son del crime, ¿no? } \\
\text { - ¿Crime? } \\
\text { - Mierda, Regis, él habla de esa } \\
\text { manera. } \\
\text { - ¡Ah! Listo. } \\
\text { - Ustedes son del crime, lo sé. } \\
\text { - Sí, somos, yo y éste mi compañero. } \\
\text { - Bueno, quieren algo, yo sé qué es, } \\
\text { pero el destino está extraño, mijo, } \\
\text { nunca se sabe quién es quién. } \\
\text { Ustedes quieren saber si el crime va } \\
\text { a ser exitoso, pero hay un perdido }\end{array}$ & $\begin{array}{l}\text { - Oi, padrino. } \\
\text { - ¡Ah! Hola, don Joel. } \\
\text { - Tú, hijo, no me llamas don, sólo } \\
\text { padrino. } \\
\text { - ¡Está bueno! } \\
\text { - Ustedes son del quimen, ¿no? } \\
\text { - ¿Quimen? } \\
\text { - Carajo, Régis, él habla así. } \\
\text { - ¡Ah, bueno! } \\
\text { - Ustedes son del quimen, lo sé. } \\
\text { - Sí. Lo somos, mi compañero aquí } \\
\text { y yo. } \\
\text { - Bueno, utede quere algo, yo sé } \\
\text { qué, pero el destino es estaño, hijo, } \\
\text { nunca se sabe quién es quién. Utede } \\
\text { quere saber si el quimen va sali } \\
\text { bien, pero hay un perdido, ta } \\
\text { vagando y ta detrá de ti. }\end{array}$ \\
\hline
\end{tabular}


que está vagando y está atrás de ustedes.

Mario Merlino reproduziu alguns aspectos da fala do pai de santo. $\mathrm{O}$ tradutor utilizou os termos 'quimen' para 'crimen' e 'estaño' para 'extraño'. As outras marcas fonéticas do diálogo foram omitidas. Usaram-se, então, os procedimentos de manutenção e omissão respectivamente.

Tennina também tenta recriar alguns aspectos da fala de Joel ao empregar os termos 'crime' para 'crimen' e a interjeição 'mijo' para 'mi hijo'. As demais marcas fonéticas foram omitidas. Ela emprega, assim como Mario Merlino, os procedimentos de manutenção e omissão. Contudo, a tradutora adiciona uma nota de rodapé na qual assume a impossibilidade da tradução total do modo como Joel se expressa. Nela, Tennina argumenta que

\begin{abstract}
Geralmente o pai de santo fala como um preto velho, viejo negro, cuja educação é através da oralidade, e sua origem é do interior do Brasil (a periferia de São Paulo é habitada, em sua grande maioria, por migrantes rurais do nordeste brasileiro). Dada a impossibilidade de reproduzir em castelhano esse modo de falar, optou-se, neste caso, pela tradução do conteúdo e não da forma. ${ }^{18}$ (TENNINA, 2011, p. 133)
\end{abstract}

A nota de rodapé, no entanto, soa contraditória, pois como foi dito anteriormente, a tradutora tenta transpor certos aspectos fonéticos da fala de Pai Joel, enquanto outros não - 'extraño' para 'estaño. Além dessa contradição, a omissão do vocativo 'pai' na primeira fala do diálogo fragiliza o humor do texto-fonte. Faz-se contraditório esse apagamento pois, na terceira fala do diálogo mencionado, utiliza-se o termo 'pai'.

Já o tradutor mexicano Alejandro Reyes mantém várias características da fala de Joel na língua espanhola. Além do uso dos termos 'quimen' para 'crimen' e 'estaño' para 'extraño', utiliza também a supressão de consoantes e vogais em 'utede quere algo' para 'ustedes quieren algo', 'ta vagando y ta detrá de ti' para 'está vagando y está detrás de ti' e 'va sali bien' para 'va a salir bien'. O

\footnotetext{
18“"Generalmente el pai de santo habla como un preto velho, viejo negro, cuya educación es a través de la oralidad, y su origen es del interior de Brasil (la periferia de San Pablo está habitada en su gran mayoría por migrantes rurales del nordeste brasileño). Dada la imposibilidad de reproducir en castellano ese modo de hablar, se optó, en este caso, para la traducción por el contenido y no la forma."
} 
procedimento de manutenção é empregado aqui, pois o tradutor utiliza marcas fonéticas da língua espanhola para tentar reproduzir o efeito que a fala do pai de santo tem no leitor e nas demais personagens do diálogo.

Em relação ao termo 'pai', somente Tennina explica o significado da palavra em seu glossário. Os demais tradutores utilizaram os termos 'padre' e 'padrino' para se referir a Joel. Embora sejam traduções adequadas sob o ponto de vista literal (ou denotativo), não parecem indicar aos leitores, a princípio, que se referem a um membro do candomblé. Nesse sentido, podese dizer que essa falta de referência pode prejudicar o humor da cena e omite um aspecto cultural do contexto de partida da obra.

O quinto trecho trata do momento em que Régis chega a uma festa onde está também Neguinho da Mancha na Mão. Em relação às marcas fonéticas, a tradução de Reyes mantém os termos ' $p a$ ' e ' $a h$ '. A de Merlino mantém a interjeição 'vixe' ao utilizar a interjeição ' $j o^{\prime}$ ', que seria um eufemismo do termo 'joder'. Tennina muda a mesma interjeição ao usar uma palavra de baixo calão como ' $p u t a$ '. Em relação às marcas morfossintáticas, a tradução de Tennina as mantém, já que utiliza os estrangeirismos 'cerva' e 'home' nas frases 'tiene hasta unas cerva' e 'los home nos agarran consumiendo'. Considerando que em espanhol, assim como no português, o -s indica flexão de número, o leitor hispano poderá apreender a não-concordância presente nos dois trechos. Mario Merlino, no entanto, muda a regência não-canônica 'ir em' para 'ir a por', considerada culta na Espanha. Na entrada 'a por', publicada na página da Fundación del Español Urgente (FundéuRAE, 2010), diz-se que essa construção "não é incorreta e no espanhol da Espanha, é própria da norma culta"19. Muda-se, então, um aspecto não-canônico da língua portuguesa para um da norma culta do espanhol peninsular.

Quanto às marcas lexicais, Mario Merlino mantém os termos 'tío', 'porro', 'esnifar', 'poli' e 'compi'. O tradutor omite os termos 'tá a pampa', 'pode crề', 'e aî', 'cara' e 'é pau no gato sem massagem'. Já Lucía Tennina mantém os termos 'jão', 'qué onda?', 'tipo', 'mano', 'boys', 'baseado', 'aspirar' e 'es una patada en los huevos'. A tradutora omite os termos 'tá a pampa' e 'pode crê', que se torna uma pergunta em sua tradução. Reyes, por sua vez, mantém os termos 'boys',

19 "No es incorrecta y en español de España es propia de la norma culta." 
'porro', 'inhalar', 'es palo en el gato sin masaje', 'tira' e 'bróder'. As palavras 'jão', 'tá a pampa', 'pode crề', 'e aî' e 'cara' são omitidas. Também usa o procedimento de adição ao usar 'ahorita' no lugar de 'agora', pois emprega uma expressão coloquial do México em um local do diálogo em que, no texto-fonte, não havia essa coloquialidade. Houve, aqui, uma compensação.

Quadro 5: Diálogo entre Régis e Neguinho da Mancha na Mão (marcas fonéticas, lexicais e morfossintáticas)

\begin{tabular}{|l|l|}
\hline FERRÉZ. Manual prático do ódio. & FERRÉZ. Manual práctico del \\
Rio de Janeiro: Objetiva, 2003. p. & odio. Tr. Mario Merlino. \\
127-128. & $\begin{array}{l}\text { Barcelona: El Aleph Editores, } \\
\text { 2006. p. 115. }\end{array}$ \\
\hline - E a festinha aí, tá gostando, jão? & - ¿Y qué? ¿Te está gustando la \\
- Tá a pampa, a pesar de ser & fiesta, tío? \\
americana, tem até umas cerva. & - Está formidable, a pesar de ser \\
- Pode crê, né, festa americana todo & americana tiene bastante cerveza. \\
mundo só leva vinho, mas o que vai & - Es verdad, a las fiestas \\
pegar? & americanas todo el mundo lleva \\
- Acho que daqui é para cama. & vino. ¿Y qué vas a hacer? \\
- E aí, tem da boa? & - Creo que de aquí me voy a la \\
- Ontem peguei uns papel & cama. \\
empastado, mas agora tô com uns & - ¿Y ahí tienes algo bueno? \\
até bonzinho! & - ¡Ayer cogí una algo floja, pero \\
- Vamo nessa então. & ahora tengo una bastante buena! \\
- Tem que dá um tempo, Régis, meu & - Vamos a por ella, pues. \\
primo tá ali, e ele é ligado nesse & - Tienes que dar un tiempo, Régis, \\
barato de contra droga. & allí está mi primo y él está metido \\
- Vixe, sério? & en esos grupos antidroga. \\
- Sério, depois que ele viu um cara & - ¡Jo! ¿En serio? \\
do rap falando lá na escola, ele & - En serio. Después de estar \\
mudou a cabeça. & hablando con un rapero en el \\
- O que o mano falou para ele, & colegio, se le trastornó la cabeza. \\
Neguinho? & $-¿ Y$ qué le dijo el tío, Neguino? \\
\hline
\end{tabular}




\begin{tabular}{|c|c|}
\hline $\begin{array}{l}\text { - Que os boys usam, fuma um } \\
\text { baseado ou cheira, e quando acorda } \\
\text { de manhã tem café da manhã bom, } \\
\text { toma suco de laranja, então os } \\
\text { sintomas não aparecem. Nós não, os } \\
\text { home pega nós usando, é pau no } \\
\text { gato sem massagem, jão, pra pobre } \\
\text { é tudo osso, sem dinheiro nem para } \\
\text { a alimentação, e fica usando isso, foi } \\
\text { mais ou menos isso que o cara disse. }\end{array}$ & $\begin{array}{l}\text { - Que los pijos consumen, fuman } \\
\text { un porro o esnifan, y cuando } \\
\text { despiertan por la mañana tienen } \\
\text { un buen desayuno, beben zumo } \\
\text { de naranja, y así los síntomas no } \\
\text { aparecen. Pero nosotros no, a } \\
\text { nosotros nos cogen los polis } \\
\text { consumiendo, es como operarte } \\
\text { sin anestesia, compi, para los } \\
\text { pobres los huesos, sin dinero } \\
\text { siquiera para comer, y no paramos } \\
\text { de consumir, fue más o menos eso } \\
\text { lo que dijo el tío. }\end{array}$ \\
\hline $\begin{array}{l}\text { Tr. Lucía Tennina. Buenos Aires: } \\
\text { Corregidor, 2011. Vereda Brasil; } 23 . \\
\text { p. 139-140. }\end{array}$ & $\begin{array}{l}\text { FERRÉZ. Manual práctico del } \\
\text { odio. Tr. Alejandro Reyes. Oaxaca: } \\
\text { sur+ ediciones, 2012. p. 146-147. }\end{array}$ \\
\hline $\begin{array}{l}\text { - ¿Y te está gustando la fiestita, jãa? } \\
\text { - Está bien, a pesar de ser americana, } \\
\text { tiene hasta unas cerva. } \\
\text { - ¿La podés creer? A fiesta americana } \\
\text { todo el mundo lleva sólo vino, pero } \\
\text { ¿qué hay para después? } \\
\text { - Creo que de acá a la cama. } \\
\text { - Y, ¿qué onda?, ¿tenés de la buena? } \\
\text { - Ayer conseguí unos papeles } \\
\text { empastados, pero ahora ando con } \\
\text { unos bastante buenos. } \\
\text { - Vamos entonces. } \\
\text { - Esperá un poco, Régis, mi primo } \\
\text { está allá, y anda en esa cosa contra } \\
\text { las drogas. } \\
\text { - Puta, ¿en serio? }\end{array}$ & $\begin{array}{l}\text { - ¿ Y la fiestecita, } i \text { te está } \\
\text { gustando? } \\
\text { - Está buena, aunque sea } \\
\text { americana, hasta hay algunas } \\
\text { cervezas. } \\
\text { - Sí, a las fiestas americanas todo } \\
\text { mundo sólo lleva vino, ¿pero qué } \\
\text { vas a hacer? } \\
\text { - Creo que de aquí me voy a la } \\
\text { cama. } \\
\text { - Oye, ¿tienes de la buena? } \\
\text { - Ayer conseguí una medio floja, } \\
\text { ¡pero ahorita traigo una bastante } \\
\text { buena! } \\
\text { - Vamos a darle, entonces. }\end{array}$ \\
\hline
\end{tabular}




\begin{tabular}{|c|c|}
\hline $\begin{array}{l}\text { - En serio, después de ver a un tipo } \\
\text { del rap hablando allá en la escuela, } \\
\text { le cambió la cabeza. } \\
\text { - ¿Qué dijo el mano, Neguinho? } \\
\text { - Que los boys consumen, fuman un } \\
\text { baseado o aspiran, y cuando se } \\
\text { despiertas al otro día hay un buen } \\
\text { desayuno, toman jugo de naranja, } \\
\text { entonces los síntomas no aparecen. } \\
\text { Nosotros no, los home nos agarran } \\
\text { consumiendo, es una patada en los } \\
\text { huevos, jão, para el pobre todo son } \\
\text { huesos, sin plata ni para la comida, } \\
\text { y se la pasa consumiendo eso, fue } \\
\text { más o menos eso lo que el tipo dijo. }\end{array}$ & $\begin{array}{l}\text { - Hay que esperar un rato, Régis, } \\
\text { mi primo está ahí, y está en esa } \\
\text { onda de contra droga. } \\
\text { - ¡Ah! ¿En serio? } \\
\text { - En serio, después de que vio a un } \\
\text { rapero hablando allá en la escuela, } \\
\text { cambió de cabeza. } \\
\text { - ¿Y qué le dijo al, Neguiño? } \\
\text { - Que los boys usan, fuman un } \\
\text { porro o inhalan, y cuando } \\
\text { despiertan en la mañana comen } \\
\text { un buen desayuno, toman jugo de } \\
\text { naranja, entonces los síntomas no } \\
\text { aparecen. Nosotros no, la tira nos } \\
\text { agarra usando y es palo en el gato } \\
\text { sin masaje, bróder, para los } \\
\text { pobres todo es hueso, sin dinero ni } \\
\text { pa la alimentación, y nos la } \\
\text { pasamos usando eso, fue más o } \\
\text { menos eso lo que el rapero dijo. }\end{array}$ \\
\hline
\end{tabular}

O último fragmento se refere ao diálogo entre Aninha e Celso Capeta. Um dos traços dos diálogos do livro é a frequência das interjeições. Essas, no entanto, desaparecem na tradução de Merlino do trecho - permanecendo apenas o termo 'mira' para 'é o seguinte, meu'. No caso da tradução de Reyes, traduz-se o primeiro 'meu' para 'mira', o segundo é omitido e o terceiro é mantido pela expressão 'mano'. A tradução de Tennina é a única que mantém a expressão, pois usa a palavra do português no texto em espanhol. 
Quadro 6: Diálogo entre Aninha e Celso Capeta (marcas lexicais)

\begin{tabular}{|c|c|}
\hline $\begin{array}{l}\text { FERRÉZ. Manual prático do ódio. } \\
\text { Rio de Janeiro: Objetiva, 2003. p. } \\
\text { 223-224. }\end{array}$ & $\begin{array}{l}\text { FERRÉZ. Manual práctico del odio. } \\
\text { Tr. Mario Merlino. Barcelona: El } \\
\text { Aleph Editores, 2006. p. } 204 .\end{array}$ \\
\hline $\begin{array}{l}\text { - Então, Aninha, preciso trocar uma } \\
\text { idéia contigo. } \\
\text { - Fala, Celso, o que pega? } \\
\text { - É o seguinte, meu, tô achando isso } \\
\text { tudo muito estranho. } \\
\text { - Estranho? } \\
\text { - É, meu, se você começar a dizer } \\
\text { que eu estou viajando, eu nem dou } \\
\text { a ideia. } \\
\text { - Pode falar, Celso, que eu também } \\
\text { não estou engolindo uns baratos aí. } \\
\text { - Então tá, primeiro cê acha que o } \\
\text { Modelo ia fazer essa guerra toda } \\
\text { por causa daquele cururu que o } \\
\text { Neguinho matou? } \\
\text { - Acho não, meu, e já tava com essa } \\
\text { dúvida faz tempo. }\end{array}$ & $\begin{array}{l}\text { - Oye, Aniña, necesito hablar } \\
\text { contigo. } \\
\text { - Dime, Celso, ¿qué pasa? } \\
\text { - Mira, todo esto me está pareciendo } \\
\text { muy extraño. } \\
\text { - ¿Extraño? } \\
\text { - Sí, pero si vas a creer que estoy } \\
\text { fantaseando, no te digo nada. } \\
\text { - Puedes hablar, Celso, que yo } \\
\text { tampoco logro entender algunas } \\
\text { cosas. } \\
\text { - Vale, pues, primero: ¿tú crees que } \\
\text { Modelo ha iniciado toda esta guerra } \\
\text { por causa de aquel desgraciado que } \\
\text { mató Neguiño? } \\
\text { - Claro que no creo en eso, hace } \\
\text { tiempo que se me había planteado } \\
\text { esa duda. }\end{array}$ \\
\hline $\begin{array}{l}\text { FERRÉZ. Manual práctico del odio. } \\
\text { Tr. Lucía Tennina. Buenos Aires: } \\
\text { Corregidor, 2011. Vereda Brasil; } 23 . \\
\text { p. 237-238. }\end{array}$ & $\begin{array}{l}\text { FERRÉZ. Manual práctico del odio. } \\
\text { Tr. Alejandro Reyes. Oaxaca: sur+ } \\
\text { ediciones, 2012. p. } 260 \text {. }\end{array}$ \\
\hline $\begin{array}{l}\text { - Bueno, Aninha, necesito hablar } \\
\text { con vos } \\
\text { - Decime, Celso, ¿qué pasa? } \\
\text { - La cosa es así, meu, todo esto me } \\
\text { está sonando muy extraño. } \\
\text { - ¿Extraño? }\end{array}$ & $\begin{array}{l}\text { - Mira, Aniña, tengo que debatir una } \\
\text { idea contigo. } \\
\text { - Habla, Celso, ¿qué hay? } \\
\text { - Lo siguiente, mira, a mí me parece } \\
\text { todo muy raro. } \\
\text { - ¿Raro? } \\
\text { - Sí, pero si me empiezas a decir que } \\
\text { estoy viajando, no digo nada. }\end{array}$ \\
\hline
\end{tabular}




\begin{tabular}{|l|l|}
\hline - Sí, pero si vas a empezar a decir & - Puedes hablar, Celso, que yo \\
que estoy delirando no te digo & tampoco me estoy tragando algunas \\
nada. & cosas. \\
- Podés hablar, Celso, que yo & - Entonces va, primero: ¿crees que \\
tampoco me trago algunas cosas. & Modelo haría toda esa guerra por \\
- Entonces listo, primero, ¿vos & causa de ese idiota que Neguiño \\
pensás que Modelo está haciendo & mató? \\
toda esta guerra por ese sapo que & - Creo que no, mano, y ya tenía esa \\
Neguinho mató? & duda desde hace tiempo. \\
- No lo creo, meu, y ya estoy con esa & \\
duda hace tiempo. & \\
\hline
\end{tabular}

No entanto, aparentemente há um erro de interpretação na tradução feita por Tennina em 'sapo' para 'cururu', pois traduziu o termo literalmente. Os demais tradutores parecem ter feito uma tradução mais próxima semanticamente do termo-fonte, embora usando palavras não-coloquiais 'idiota' e 'desgraciado'. Nesse sentido, todo omitiram essa marca específica. Outra marca lexical omitida por todos os tradutores foi 'uns baratos', traduzida por 'algunas cosas'. Mario Merlino mantém a coloquialidade de 'então tá' em 'vale', mas eleva o tom em algumas partes como 'tampoco logro entender' para 'não estou engolindo' e 'se me había planteado esa duda' para 'tava com essa dúvida'. O mesmo não acontece nas outras traduções, que mantêm o tom do texto. As marcas fonéticas do fragmento são omitidas em todas as traduções.

A partir da análise desses seis trechos, pode-se dizer que todas as traduções omitiram parte das marcas lexicais, fonéticas e morfossintáticas da língua de partida. Tendência, essa, natural a todo processo tradutório. No entanto, quando as mantêm, a preferência parece ser dada às (i) marcas lexicais, pois todas as traduções apresentam tentativas consistentes e sistemáticas de mantê-las. Em relação às (ii) marcas fonéticas, a única tradução que apresenta tentativas consistentes de mantê-las é a mexicana, de Alejandro Reyes. Já quanto às (iii) marcas morfossintáticas, a única tradução que as mantém sistematicamente é a de Lucía Tennina, por meio de uso de estrangeirismos do português 'homi', 'home', 'cerva'. 
Levando em consideração, então, as estratégias e resultados descritos por Rosa (2012), as três traduções seriam centralizadoras. Em outras palavras, apresentariam um movimento em direção à padronização da língua, mas tentariam, em alguma medida, manter a variedade linguística presente no texto-fonte (2012, p. 89-90). No entanto, essa centralização não "aconteceria" do mesmo modo e no mesmo grau em cada tradução. Se consideramos a quantidade e os tipos de marcas preservadas em cada tradução, poderíamos dizer que a tradução peninsular seria a menos centralizadora, já que apenas as marcas lexicais são consistentemente mantidas. Já a tradução argentina, por manter marcar lexicais e morfossintáticas, e a tradução mexicana, por manter marcas lexicais e fonéticas, seriam mais centralizadoras. Tem-se em vista aqui também o fato de que as duas últimas traduções apresentam preocupação consistente de utilizar termos da língua de partida no texto de chegada. Essa preocupação se verbaliza e se materializa para além da letra do texto traduzido. Podem-se encontrar declarações nesse sentido em materiais paratextuais produzidos pelos tradutores - prefácios, entrevistas, trabalhos acadêmicos. Essas traduções buscariam, assim, dar visibilidade à periferia descrita por Ferréz.

Desse modo, pode-se dizer que as três traduções tenderiam a heteroglossia, já que mantêm certos aspectos variacionais do texto de partida. Contudo, a tradução peninsular, pelo uso de menos tipos de marcas de oralidade e pela aparente não-consideração do projeto político-literário do autor, apresentaria um grau menor de heteroglossia. Já as traduções argentina e mexicana apresentariam um grau maior de heteroglossia, pois mantêm mais tipos de marcas e buscam utilizar, de maneira sistemática e consistente, estratégias linguísticas e paratextuais que visibilizem o projeto políticoliterário de Ferréz.

\section{CONSIDERAÇÕES FINAIS}

Conclui-se, então, que as hipóteses aventadas no início deste artigo, isto é, de que a tradução de variedade tem como pontos importantes (i) a traduzibilidade, (ii) a padronização e (iii) a artificialidade, confirmam-se em parte. As traduções argentina e mexicana, por conta do uso consistente de estrangeirismos - refletidos em glossários e notas de rodapé - parecem 
reconhecer que o texto e o projeto político-literário de Ferréz têm certo grau de "intraduzibilidade", restando, então, aos tradutores mesclar falares da língua de chegada com falares da língua de partida. Quanto à padronização, considera-se a tradução peninsular mais padronizadora do que as outras duas, já que usa frequentemente apenas um tipo de marca de oralidade. As traduções argentina e mexicana empregam mais tipos de marcas de modo sistemático. Por fim, em relação à artificialidade, a tradução peninsular não soaria artificial, pois não mescla falares da língua de partida e da língua de chegada, sendo, portanto, mais domesticadora. As traduções de Tennina e Reyes, por conta dessa mescla de falares, criam uma espécie de "fala híbrida" (AZEVEDO, 2003), tornando os textos mais estrangeirizantes e, nesse sentido, mais artificiais.

\section{Referências bibliográficas}

AZEVEDO, Milton. Vozes em branco e preto: a representação literária da fala não padrão. São Paulo: Edusp, 2003.

BERMAN, Antoine. Toward a Translation Criticism: John Donne. Tradução e edição de Françoise Massardier-Kenney. Kent, Ohio: Kent State University Press, 2009.

BRITTO, Paulo Henriques. A tradução literária. Rio de Janeiro: Civilização Brasileira, 2012.

COLLINS, Georgina; PONZ, María López. Translation, hybridity and borderlands: translating non-standard language. In: Harding, Sue-Ann; Carbonell Cortés, Ovidi (ed). The Routledge Handbook of Translation and Culture. New York: Routledge, 2018, p. 398-414.

CURI, Matheus Oliveira Paiva. Os tradutores são mais confiáveis: a variação linguística nas traduções para o espanhol do capítulo um de Manual prático do ódio. Revista Entrecaminos, 2021, v. 5, n. 1 (no prelo).

ENCICLOPÉDIA Itaú Cultural de Arte e Cultura Brasileiras. Ferréz. São Paulo: Itaú Cultural, 2021. Disponível em: http://enciclopedia.itaucultural.org.br/pessoa280342/ferrez. Acesso em: 03 jun. 2021. Verbete da Enciclopédia. 
FARIA, Tatiana Lima. Intersecção entre mercado editorial e pesquisa acadêmica: análise da coleção Vereda Brasil. 2016. Dissertação (Mestrado em Língua Espanhola e Literaturas Espanhola e Hispano-Americana) Faculdade de Filosofia, Letras e Ciências Humanas, Universidade de São Paulo, São Paulo, 2016. doi:10.11606/D.8.2017.tde-03042017-125156. Acesso em: 02 jun. 2021.

FERRÉZ. MANUAL PRÁTICO DO ÓDIO. Youtube, 27 jul. 2020. Disponível em: https://www.youtube.com/watch?v=-yX1Lv0oImU. Acesso em: 02 jun. 2021.

FERRÉZ. Manual práctico del odio. Traducción de Alejandro Reyes. Oaxaca: sur+ ediciones, 2012.

FERRÉZ. Manual práctico del odio. Comentado por Arnaldo Antunes [et al]. Prólogo y traducción de Lucía Tennina. Buenos Aires: Corregidor, 2011. Vereda Brasil; 23.

FERRÉZ. Manual práctico del odio. Traducción de Mario Jorge MerlinoTornini. Barcelona: El Aleph Editores, 2006.

FERRÉZ. Literatura Marginal. 2006. Disponível em: http://editoraliteraturamarginal.blogspot.com/2006/10/literaturamarginal.html. Acesso em: 31 ago. 2021.

FERRÉZ. O que é 1dasul???. 2005. Disponível em: http://blog.ferrezescritor.com.br/2005/06/o-que-1dasul.html. Acesso em: 02 jun. 2021.

FERRÉZ. Manual prático do ódio. Rio de Janeiro: Objetiva, 2003.

FUNDACIÓN DEL ESPAÑOL URGENTE (FundéuRAE). A por. 2010. Disponível em: https://www.fundeu.es/consulta/a-por-1720/. Acesso em: 07 set. 2021.

GENETTE, Gérard. Paratextos editoriais. Tradução Álvaro Faleiros. Cotia, SP: Ateliê Editorial, 2009.

ROSA, Alexandra Assis. Translating Place: Linguistic Variation in Translation. Word and Text: A Journal of Literary Studies and Linguistics. Vol. II, Issue 2, p. 75-97, December 2012.

SADIER, Emilio. Narrar el margen: visibilidades, ritmos y juegos. In: ACUÑA, Ezequiel [et al.]. Voces desde el margen: Literatura y favela: seis ensayos sobre Manual práctico del odio. Compilado por Lucía Tennina. Buenos Aires: EDEFYL, 2013, p. 23-37. 
SUR+. Manifiesto. [2018?] Disponível em: http://surplusediciones.com/manifiesto. Acesso em: 04 jun. 2021.

\section{Resumo}

Este artigo investiga como três traduções do romance Manual prático do ódio (Objetiva, 2003), de Ferréz, foram feitas para as variedades argentina, mexicana e peninsular da língua espanhola. Analisando fatores textuais tradução das variedades não-padrão - e fatores paratextuais (GENETTE, 2009), procurou-se compreender como os aspectos supracitados refletiriam o projeto político-literário de Ferréz para os mercados onde essas traduções circularam. Além disso, procurou-se compreender como esses aspectos refletiriam questões importantes da tradução de variedade linguística, como a traduzibilidade, a padronização e a artificialidade.

Palavras-chave: Crítica de tradução; Ferréz; Literatura marginal; Variação linguística; Espanhol

\section{Resumen}

Este artículo investiga cómo se tradujo la novela Manual prático do ódio (Objetiva, 2003), de Ferréz, para las variedades argentina, mexicana y peninsular de la lengua española. A través del análisis de factores textuales - traducción de variedades no estándares - y factores paratextuales (GENETTE, 2009), se procuró comprender como los aspectos mencionados reflejarían el proyecto político-literario de Ferréz hacia los mercados donde esas traducciones han circulado. Además, se procuró comprender como esos aspectos reflejarían cuestiones importantes de la traducción de la variedad lingüística, como la traducibilidad, la estandarización y la artificialidad.

Palabras-clave: Crítica de la traducción; Ferréz; Literatura marginal; Variación lingüística; Español 